\title{
The Prevalence of Illegal Drug Use
}

\section{Doi:10.5901/ajis.2014.v3n3p530}

\author{
Doc. Dr. Fiona Todhri
}

\section{Abstract}

The prevalence of the use of only one type of illicit drug, except marijuana or hashish, ranging from $0.4 \%$ to $14.3 \%$ for different substances. Psychoactive drugs used by participants aged 13-34 years in our study, are sedatives and tranquilizers without a prescription. Lifetime prevalence of consumption of sedatives without prescription resulted $14.3 \%$ of boys and girls reported similar prevalence (14.1\% respectively $14.6 \%$ boys versus girls). For all other psychoactive substances illegal, the prevalence was significantly higher among men than among women. The aim of this study has been to undertake an in depth analysis of the prevalence, tendencies, and factors related to the use of psycho active substances among youth in Albania and evaluation of social services offered in the country. The objective of the study is the Determination of the prevalence and frequency of consumption of illegal drugs and their relation to socio-demographic and economic factors. This study is transversal (crosssectional), the only type of study which allows interest phenomenon prevalence evaluation. In this study are included two subject groups: one group consists of subjetcs currently present at education system and interviewed at school settings, i.e secondary schools, high schools and university. The other group consists of youngsters being interviwed not at schools settings.

Keywords. Prevalence, Illegal drug use, Young people

\section{Illegal Psychoactive Substances use at Young People in Albania}

In this section results related to illegal drugs use are presented: over the counter sedatives, ecstasy, amphetamines, LSD, cocaine and heroine.

$16.2 \%$ of the participants knew people who used ecstasy, $6.7 \%$ knew people who used amphetamines, 19.2\% know people who use cocaine, $16.6 \%$ know people who use heroine and $2.4 \%$ of the participants knew closely people who used LSD.

\section{Prevalence of Illegal Drugs use}

Prevalence of only one type of illegal drug use, apart from marijuana or hashish, varies from $0.4 \%$ to $14.3 \%$ for different substances. (Relevine is control variable) (Graph1). Psychoactive drugs used by participants of the age group 13-34 years old in our study, are sedatives and over-the-counter sedatives. Lifetime prevalence of over-the-counter sedatives use has been $14.3 \%$ and girls and boys have reported similar prevalence (respectively, 14.1\% girls versus 14.6\% boys). For all other illegal psychoactive substances, prevalence is significantly higher among males than females (Graph 2).

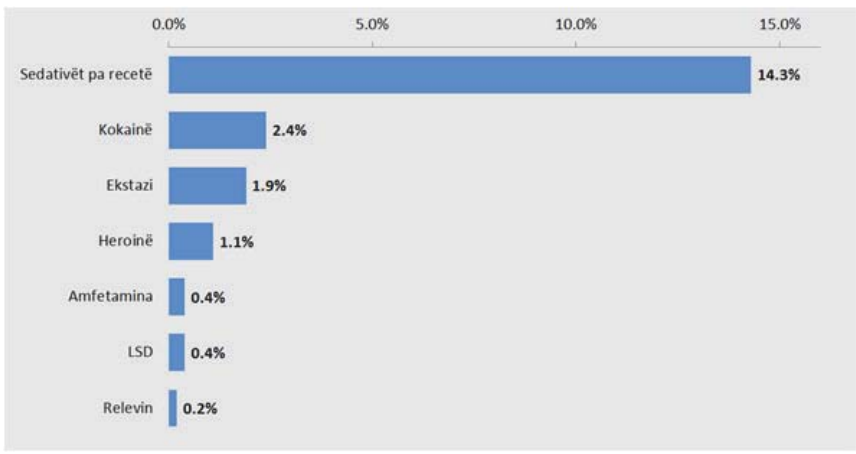

Graph 1. Lifetime prevalence of illegal drugs use 


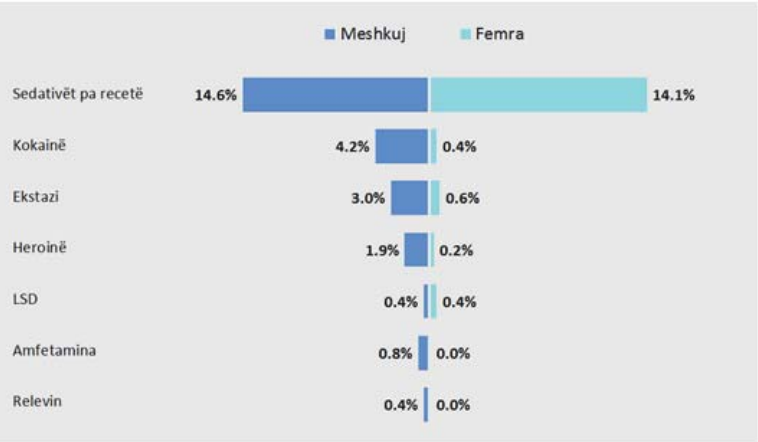

Graph 2. Lifetime prevalence of sedatives use at girls and boys

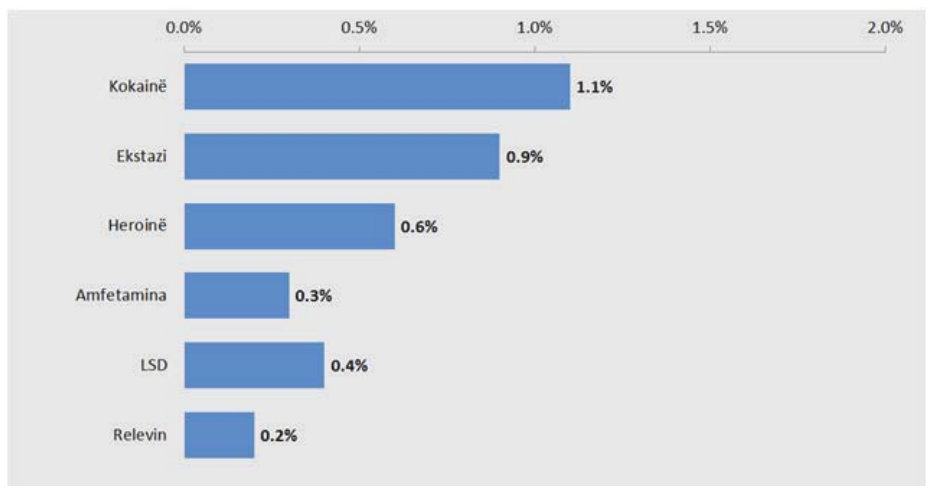

Graph 3. Lifetime prevalence illegal drug use during the last year

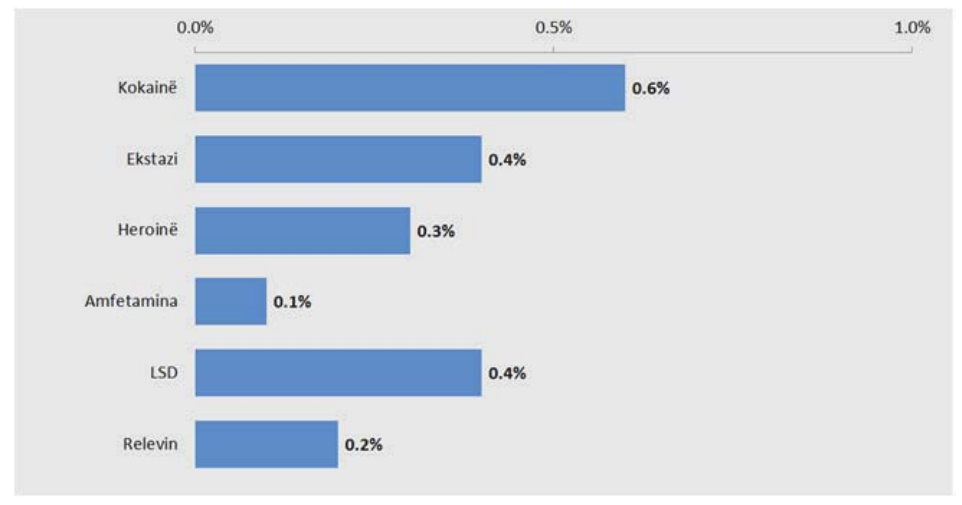

Graph 4. Lifetime prevalence illegal drug use during the last month

Related to the number of illegal substances used by the participants in the study, following Graph 5 and Table 18 provide some detailed information. Here, only illegal drug users have been shown: marijuana, over the counter sedatives, ecstasy, amphetamines, cocaine, heroine and LSD, thus, in total seven types of illegal psychoactive substances.

The data show that $13.1 \%$ of the participants used only one type of illegal drug, 1.9\% used two types of illegal drugs, whereas prevalence of three or more drugs by the same person varied from $0.4 \%$ to $0.1 \%$ (Graph 5 ). 


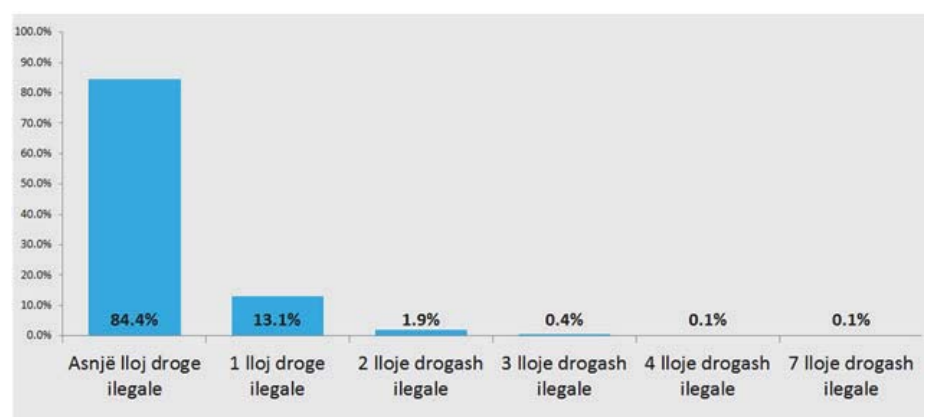

\section{Subject Distribution According to the Number of Illegal Drugs that are Used}

The completed study showed that there are no significant differences between the use of only one or more types of illegal drugs according to the gender, age group and monthly incomes, even though the trends are clearly in favor of males, older age group and those with higher monthly incomes. While the prevalence of one or more types of illegal drug use is significantly higher among large urban areas residents (Table 1).

Tabela 1: Subjects spreadby number of drugs use during the lifetime

\begin{tabular}{|c|c|c|c|c|}
\hline \multirow{3}{*}{ Variable } & \multicolumn{4}{|c|}{ How illegal drug do you have used during lifetime? } \\
\hline & \multicolumn{2}{|c|}{ No illegal drug use } & \multicolumn{2}{|c|}{$\geq 1 \mathrm{kind}$ of illegal drug } \\
\hline & Number & Pecent ${ }^{*}$ & Number & Pecent \\
\hline $\begin{array}{l}\text { Sex }{ }^{A} \\
\text { Male } \\
\text { Female } \\
\text { Total }\end{array}$ & $\begin{array}{l}442 \\
405 \\
847\end{array}$ & $\begin{array}{l}83.6 \\
85.3 \\
84.4\end{array}$ & $\begin{array}{c}87 \\
70 \\
157\end{array}$ & $\begin{array}{l}16.4 \\
14.7 \\
15.6\end{array}$ \\
\hline $\begin{array}{l}\text { Grup-age }{ }^{A} \\
\text { 13-18 year } \\
\text { 19-34 Year }\end{array}$ & $\begin{array}{l}428 \\
419\end{array}$ & $\begin{array}{l}85.8 \\
83.0\end{array}$ & $\begin{array}{l}71 \\
86\end{array}$ & $\begin{array}{l}14.2 \\
17.0\end{array}$ \\
\hline $\begin{array}{l}\text { Lloji i vendbanimit }{ }^{B} \\
\text { Urban centre area } \\
\text { Urban periferic centre area } \\
\text { Small city } \\
\text { Rural Area }\end{array}$ & $\begin{array}{l}275 \\
121 \\
122 \\
329\end{array}$ & $\begin{array}{l}79.7 \\
86.4 \\
83.6 \\
88.2\end{array}$ & $\begin{array}{l}70 \\
19 \\
24 \\
44\end{array}$ & $\begin{array}{l}20.3 \\
13.6 \\
16.4 \\
11.8\end{array}$ \\
\hline $\begin{array}{l}\text { Type of educationc } \\
\text { Primary education } \\
\text { Hight School } \\
\text { University } \\
\text { Not education }\end{array}$ & $\begin{array}{c}98 \\
341 \\
96 \\
305\end{array}$ & $\begin{array}{l}89.1 \\
84.8 \\
71.1 \\
87.4\end{array}$ & $\begin{array}{l}12 \\
61 \\
39 \\
44\end{array}$ & $\begin{array}{l}10.9 \\
15.2 \\
28.9 \\
12.6\end{array}$ \\
\hline $\begin{array}{l}\text { Month income }{ }^{A} \\
<10.000 \text { lekë } \\
10.000-20.000 \text { lekë } \\
20.001-40.000 \text { lekë } \\
>40.000 \text { lekë }\end{array}$ & $\begin{array}{l}89 \\
161 \\
224 \\
373\end{array}$ & $\begin{array}{l}90.8 \\
86.6 \\
83.9 \\
82.3\end{array}$ & $\begin{array}{c}9 \\
25 \\
43 \\
80\end{array}$ & $\begin{array}{c}9.2 \\
13.4 \\
16.1 \\
17.7\end{array}$ \\
\hline
\end{tabular}

Përqindja sipas rreshtave

A $P>0.05$ sipas testit statistikor hi katror.

$B P=0.016$ sipas testit statistikor hi katror.

${ }^{c} \mathrm{P}<0.001$ sipas testit statistikor hi katror.

About one in twenty participants (4.8\%) claimed that they had had sexual intercourse under drug effects. 


\section{Age at the Onset of Illegal Drug Use}

Regarding the average age at the onset of illegal drug use it is seen that, LSD use includes younger ages (15.5 years old \pm 3.0 years), whereas for the ecstasy a higher average group age is reported (20.6 years old \pm 4.5 years).

Average age at the onset of other illegal drug use is shown in Graph 5.

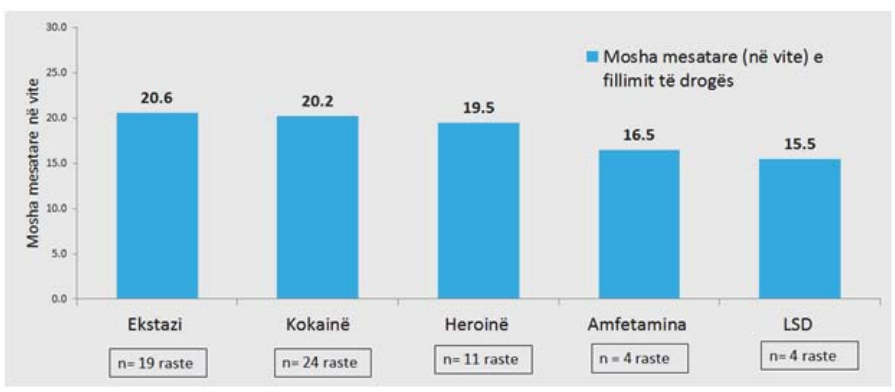

Graph 5 . Average age of illegal drug use for the first time

\section{Places Where Illegal Drugs are Usually Used}

Participants who claimed to have used ecstasy, cocaine or heroine during their lifetime, were asked about the common places where they used these substances. Like other ADDT-s, it has resulted that these substances are used in more than one place. For instance, $42.1 \%$ of the ecstasy users claimed that they usually use cannabis in cafes or clubs. According to the data, none uses ecstasy at home $(0.0 \%)$, while $5.3 \%$ of the subjects claimed that they use it in the streets, $10.5 \%$ at the parks and the same is true for school environment. Subject distribution according to the place where other illegal drugs are used, is shown in Graph 6.

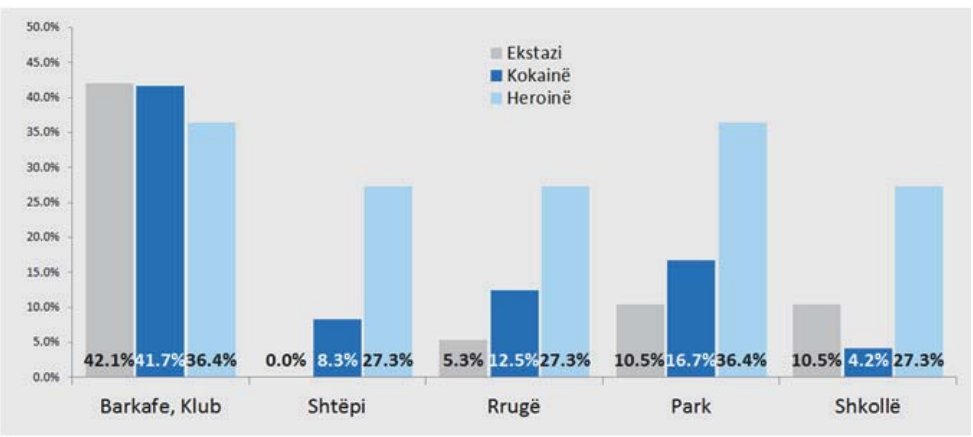

Graph 6. Prevalenca of illegal drug related to the places

\section{Conclusions}

- Alcohol use, smoking and illegal drugs prevalence in Albania in general is comparable to other regional countries, but lower compared to EU countries.

- Despite the existence of a complete legal frame related to smoking and alcohol use limitation and banning of illegal drugs, again teenagers and youth are able to find these products.

- High-risk groups for alcohol use, smoking and illegal drugs are males, aged 19-34, living in large urban areas and those with high monthly incomes. Relation to education is non-coexistent: high education is a risk factor for smoking, sedatives, but not for alcohol, cannabis or other types of illegal drugs.

- In Albania, in years a low prevalence (compared to European countries) of psychoactive substances among teenagers has dominated and continues to dominate, fluctuating slightly from 2005 to 2011. 
- On the other hand, prevalence of psychoactive substances' use among adults has been increasing over a 10year period of time in Albania. Lifetime smoking prevalence has increased over 30\% in 2011 compared to 2001, while data on smoking prevalence trends are very few. Also, assessment of illegal drugs use trends is difficult because of few official reliable resources. Compared to 2010, it has been noticed a slight increase in the prevalence of illegal drugs use among the youth in our country.

- Alcohol, smoking and cannabis use prevalence monitoring is very important, because smoking and alcohol onset is usually followed by cannabis use, which then could lead to experimentation with other "heavy" illegal drugs such as amphetamines, heroine and cocaine, as suggested by "pathway" theory. In this context, taking measures to strengthen the law, regarding teenagers' access to alcohol and smoking products is an imperative duty of public authorities. On the other hand, one in ten teenagers aged 13-34 have used cannabis at least one. This level of prevalence is translated into thousands individuals, exposing those to increased risks to experimentation with other illegal drugs according to pathway theory. Thus, monitoring and keeping under control of this narcotic substance should be a center of attention for corresponding authorities.

- A considerable percentage of individuals aged 13-34 started experimentation with alcohol at the age of 12 or younger. Since starting alcohol and smoking at a younger age implies a greater likelihood to continue using them, their abuse and starting other illegal drugs is more likely. According to pathway theory, it is necessary to regulate preventive programs at schools so that average age at the onset of these substances increases.

- Main places where alcohol, smoking, ecstasy, cocaine and heroine are used are undoubtedly cafes or different clubs in the country. Since alcohol should not be served to individuals under 18 and smoking is not allowed to be used by all ages in public places, it is implied that law is not in its highest level. Since studies showed that strict law can lead to the reduction of these substances, then this represents a relatively simple and effective

\section{References} way in this direction.

The European Monitoring Centre for Drugs and Drug Addiction. 2011 national report (2010 data) to the EMCDDA by the Reitox national focal point: Albania.

Substance Abuse and Mental Health Services Administration (SAMHSA). Results From the 2005 National Survey on Drug Use and Health: National Findings. Rockville, MD: SAMHSA, Office of Applied Studies, 2006.

Perkonigg A, Lieb R, Wittchen HU. Substance use, abuse and dependence in Germany: a review of selected epidemiological data. European Addiction Research 1998: 4:8-17.

Neurosciene of psychoactive substance use and dependence. World Health Organization. Geneva 2004.

MacDonald S, Anglin-Bodrug K, Mann RE, Erickson P, Hathaway A, Chipman M, Rylett M. Injury risk associated with cannabis and cocaine use. Drug and Alcohol Dependence 2003; 72:99-115.

Instituti i Shendetit Publik. Studim i sjelljeve me risk tek te rinjte e shkollave tw mesme ne vendin tone 2009. 